\title{
Matrix metalloproteinases (MMPs) in the endometrium of bitches
}

\author{
Po-yin Chu ${ }^{1}$, L. A. Salamonsen ${ }^{2}$, C. S. Lee ${ }^{1}$ and P. J. Wright ${ }^{1}$ \\ ${ }^{1}$ Department of Veterinary Science, The University of Melbourne, 250 Princes Hwy, \\ Werribee, Victoria 3030, Australia; and ${ }^{2}$ Prince Henry's Institute of Medical Research, \\ PO Box 5152, Clayton, Victoria 3168, Australia
}

The relationships between activities of matrix metalloproteinases (MMPs) in the canine uterus and the occurrence of degeneration of the luminal epithelium, cystic endometrial hyperplasia, pyometra and uterine remodelling post partum were determined. Mature bitches $(n=10)$ were ovariectomized, treated with hormones (oestradiol benzoate, progestagen) and investigated at stages simulating pro-oestrus $(n=2)$, oestrus $(n=2)$, dioestrus $(n=2)$, and mid- $(n=2)$ and late $(n=2)$ anoestrus ( 3 and 9 weeks, respectively, after cessation of treatment with progestagen). Untreated bitches ( $n=1$ per group) served as controls (Expt 1). An additional 10 ovariectomized bitches, at the end of treatment-induced simulated dioestrus, were treated each day for a further 3 weeks either with the same dose (standard dose, $n=3)$, a decreased dose $(n=3)$ or an increased dose $(n=3)$ of progestagen, or no treatment (withdrawal dose, $n=1$ ). These bitches were then investigated (Expt 2). A suture was placed in the lumen of one uterine horn of another five bitches at ovariectomy. Three of these bitches were treated to induce simulated dioestrus and two bitches served as untreated controls. In the hormonetreated bitches, the suture resulted in cystic endometrial hyperplasia in one bitch and in cystic endometrial hyperplasia with pyometra in two bitches. The control bitches showed no cystic endometrial hyperplasia or pyometra (Expt 3). Four intact bitches were studied at 2 $(n=1), 3 \quad(n=2)$ and $11 \quad(n=1)$ weeks post partum. Uterine tissues were also collected from two bitches with naturally occurring cystic endometrial hyperplasia with pyometra (Expt 4). All uteri were examined histologically and the activities of MMP-2, -7 and -9 (latent and active forms) were assessed using zymography of extracts of endometrium. In Expts 1 and 2, marked degeneration of the luminal epithelium in six of 25 bitches (simulated midanoestrus, withdrawal dose and decreased dose groups) was not associated with changes in MMP activities. Markedly increased activities of MMP-2 (active form), -7 (latent form) and -9 (active and latent forms) were observed in the bitches with cystic endometrial hyperplasia with pyometra (but not with cystic endometrial hyperplasia alone) and in the bitches at 2 and 3 weeks post partum (but not at 11 weeks post partum). These results indicate that MMPs are not involved with degeneration of the luminal epithelium, but are involved with uterine remodelling in the postpartum bitch and with cystic endometrial hyperplasia with pyometra.

\section{Introduction}

Significant changes in the structure of the canine endometrium are associated with degeneration of the luminal epithelium, cystic endometrial hyperplasia, pyometra and uterine remodelling post partum. The basic mechanisms associated with these changes are poorly understood. Matrix metalloproteinases (MMPs) are associated with endometrial remodelling in humans (Rodgers et al., 1994; Marbaix et al., 1995; Irwin et al., 1996; Salamonsen and Woolley, 1999), rats (Wilson et al., 1995; Woessner, 1996; Wolf et al., 1996) and sheep (Salamonsen et al., 1995). There are no studies of MMPs in the canine endometrium. The aims of the present study were to determine whether MMPs are associated with the degeneration of the luminal epithelium, cystic endometrial hyperplasia, pyometra and uterine remodelling post partum. The present study used ovariectomized bitches in a

Email: p.chu2@pgrad.unimelb.edu.au model that simulated the uterine changes that occur during the oestrous cycle of intact bitches (Chu et al., 2001a), intact bitches post partum, ovariectomized bitches with induced cystic endometrial hyperplasia with or without pyometra and bitches with naturally occurring cystic endometrial hyperplasia with pyometra. Endometrial MMP activities were evaluated using gelatin and casein zymography.

\section{Materials and Methods}

\section{Animals}

Thirty clinically normal greyhound bitches (aged 2-4 years, and had not been pregnant previously or treated with oestrogens or progestagens) and four postpartum bitches of mixed breeding housed in similar runs in the university dog colony were studied. The uteri from two bitches with naturally occurring cystic endometrial hyperplasia (CEH) with pyometra were also studied. The 30 greyhound bitches 

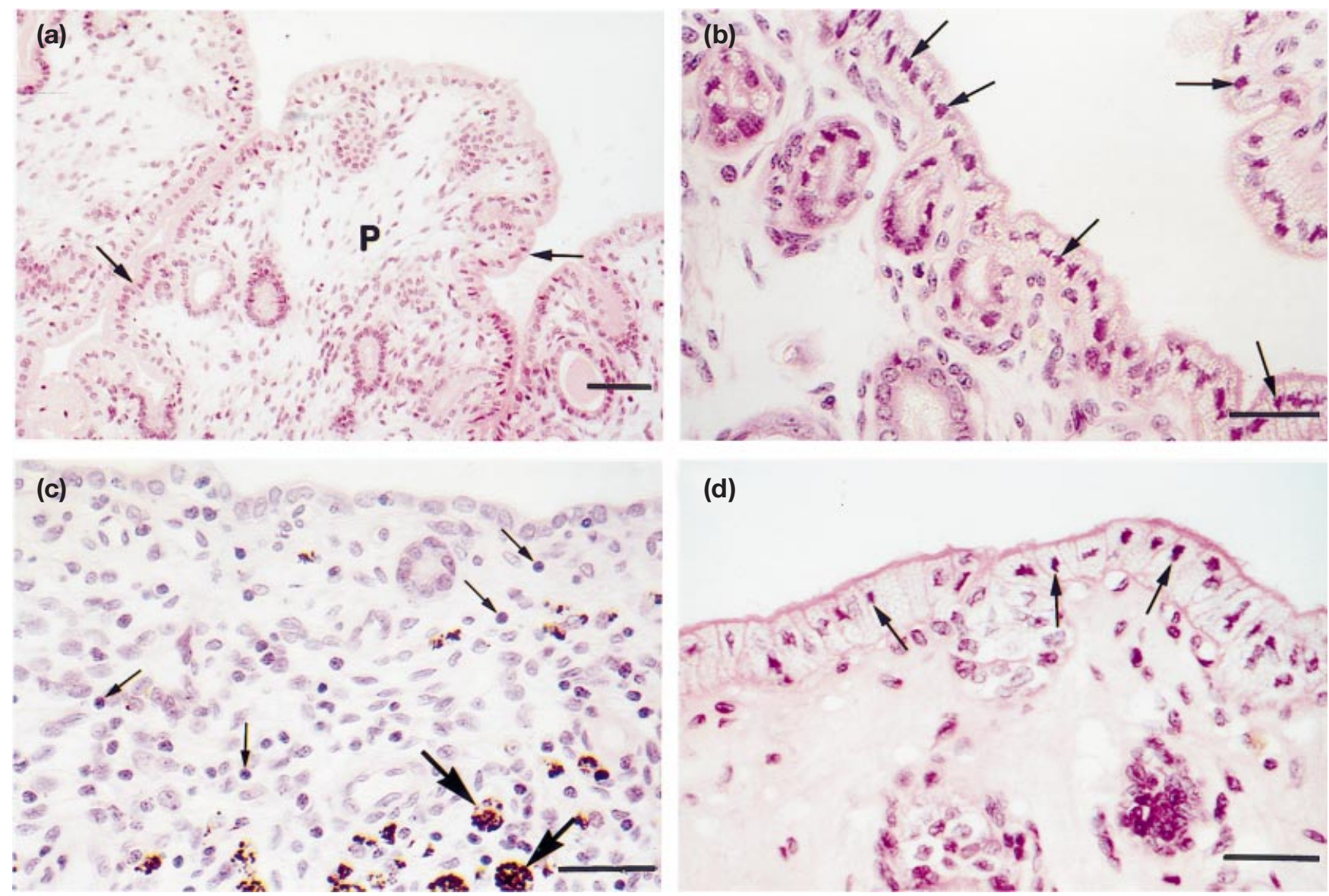

(d)

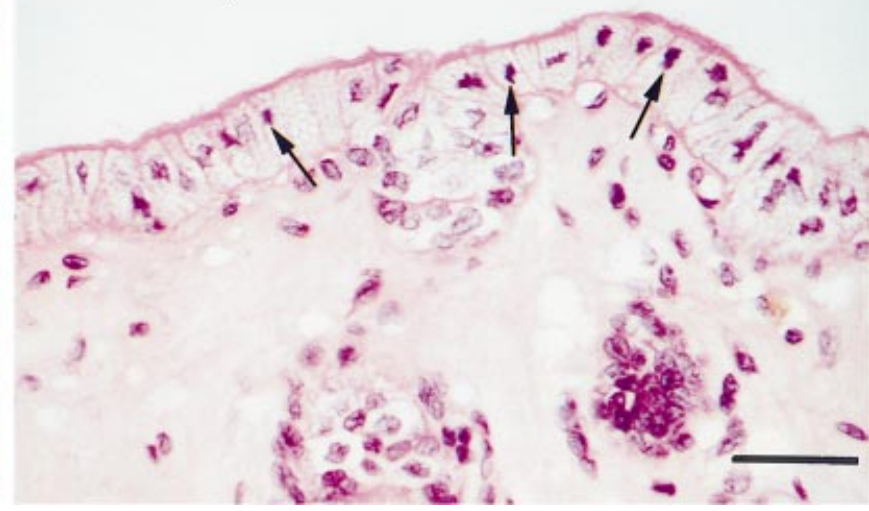

Fig. 1. (a) Light micrograph of a uterine section taken from a bitch in the dioestrous group (treated with oestradiol benzoate for 11 days then megestrol acetate for 36 days) showing the presence of primary $(\mathrm{P})$ and secondary folds (arrows) in the endometrium. The luminal epithelial cells are tall columnar. Note that very few leucocytes are present in the epithelia and stroma. (b) Light micrograph of a uterine section taken from a bitch in the mid-anoestrous group (treated with oestradiol benzoate for 11 days then megestrol acetate for 36 days, and killed 3 weeks after treatment) showing that all the luminal epithelial cells have shrunken, pyknotic nuclei (arrows) and highly vacuolated cytoplasm. (c) Light micrograph of a uterine section taken from a bitch in the late anoestrous group (treated with oestradiol benzoate for 11 days then megestrol acetate for 37 days, and killed 9 weeks after treatment). Note that the luminal epithelial cells are cuboidal and there are no signs of degeneration. Numerous lymphocytes (small arrows) and macrophages heavily laden with haemosiderin (large arrows) are present in the stroma. (d) Light micrograph taken from a bitch in the decreased dose group (treated with oestradiol benzoate for 11 days, then megestrol acetate $\left(2 \mathrm{mg} \mathrm{kg}^{-1}\right)$ once a day for 36 days, followed by megestrol acetate $\left(0.5 \mathrm{mg} \mathrm{kg}^{-1}\right)$ once a day for 3 weeks). All the luminal epithelial cells have shrunken, pyknotic nuclei (arrows) and highly vacuolated cytoplasm. Haematoxylin and eosin stain; scale bars represent (a) $50 \mu \mathrm{m}$ and (b,c,d) $30 \mu \mathrm{m}$. This figure was first published in the Journal of Reproduction and Fertility Supplement 57 (2001).

were ovariectomized during anoestrus through a mid-line laparotomy incision and general anaesthesia induced and maintained with propofol (Rapinovet, Schering-Plough, North Ryde) and halothane (Halothane, Veterinary Companies of Australia, Artarmon). The bitches were in anoestrus as determined from physical examination, vaginal cytology, uterine cytology and plasma progesterone concentrations. After 4 weeks, these bitches were treated as described below. At the end of the treatment periods, the bitches were killed with sodium pentobarbital $\left(1-2 \mathrm{ml}(5 \mathrm{~kg})^{-1}\right.$, i.v., Valabarb, Jurox Pty Ltd, Silverwater). The histological results from these studies have been reported (Chu et al., 2001a,b). The four postpartum bitches were killed at different stages post partum. The histological features of the uteri of the bitches post partum and uteri of bitches with naturally occurring CEH with pyometra are summarized. The present study reports the MMP data for all bitches. All the protocols for the experiments were approved by the Animal Experimentation Ethics Committee of the Faculty of Veterinary Science, The University of Melbourne.

\section{Experiment 1}

This experiment was performed to validate a model that simulated uterine changes that occur during the normal oestrous cycle (Chu et al., 2001a). Ten ovariectomized bitches were treated with oestradiol benzoate (Intervet, Castle Hill; 0.6-4.8 $\mu_{\mathrm{g} \mathrm{kg}}{ }^{-1}$, i.m. twice per day) for 7 days 

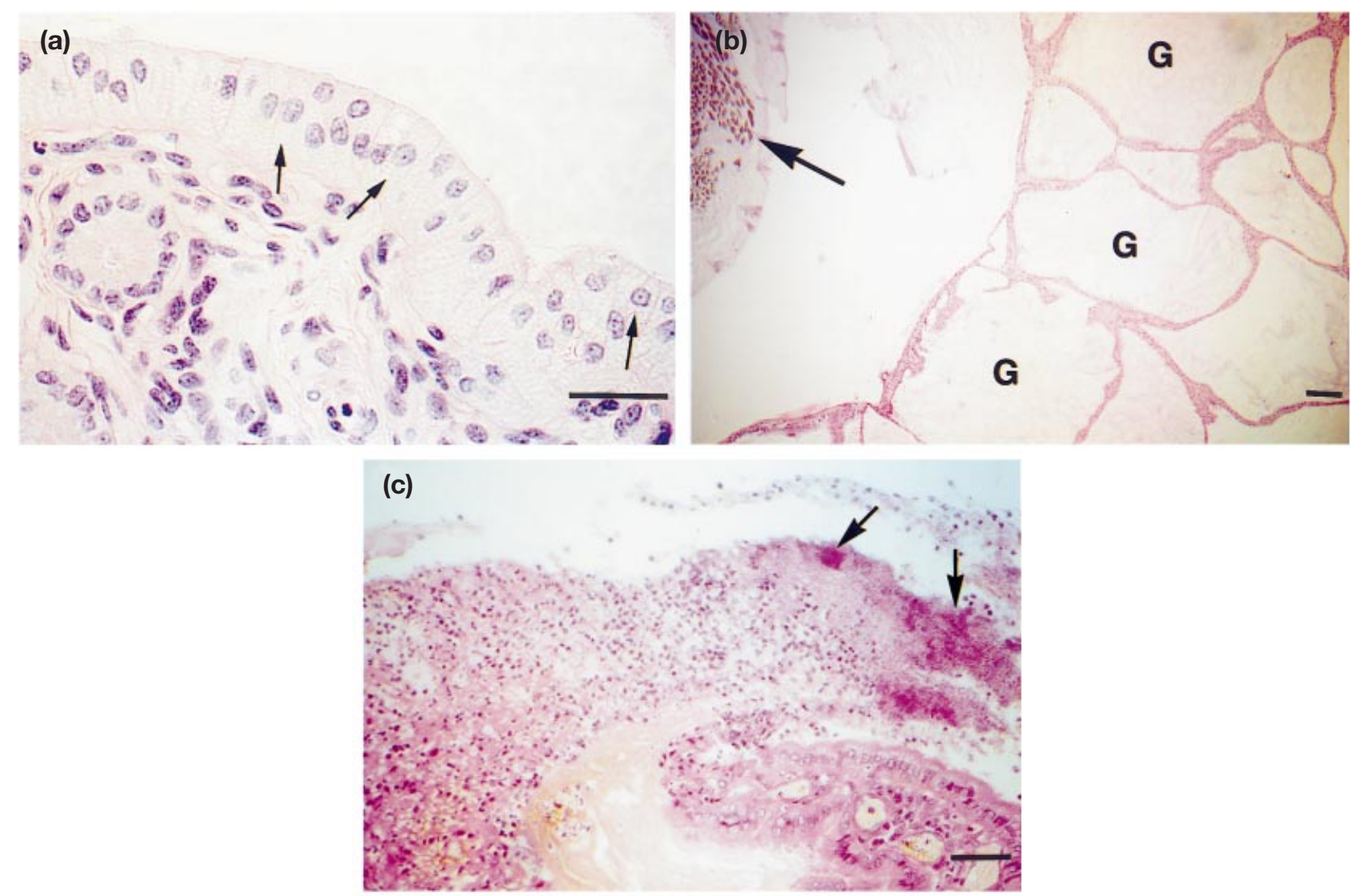

Fig. 2. (a) Light micrograph taken from a bitch in the increased dose group (treated with oestradiol benzoate for 11 days, then megestrol acetate for 35 days, followed by megestrol acetate at 3, 4 and $5 \mathrm{mg} \mathrm{kg}^{-1}$ per day in 3 successive weeks). Most of the luminal epithelial cells (arrows) are normal. (b) Light micrograph of a uterine section from an ovariectomized bitch treated with oestradiol benzoate for 11 days and then megestrol acetate for 37 days, with a silk suture in the lumen of the uterine horn. Note that the superficial glands (G) located closest to the suture (arrow) are markedly dilated. (c) Light micrograph of a uterine section taken from an ovariectomized bitch (with a silk suture in the lumen of the uterine horn and treated with oestradiol benzoate for 11 days then megestrol acetate for 35 days) with cystic endometrial hyperplasia and pyometra. Note that masses of cellular debris and clusters of bacteria (arrows) are present in the lumen. Haematoxylin and eosin stain; scale bars represent (a) $30 \mu \mathrm{m}$, (b) $100 \mu \mathrm{m}$ and (c) $50 \mu \mathrm{m}$. This figure was first published in the Journal of Reproduction and Fertility Supplement 57 (2001).

(pro-oestrous group; $n=2$ ), or with oestradiol benzoate for 11-12 days and then with megestrol acetate (Ovarid, Jurox Pty Ltd, Silverwater; $2 \mathrm{mg} \mathrm{kg}^{-1}$, p.o. once per day) for 4 days (oestrous group; $n=2$ ), or with oestradiol benzoate and then megestrol acetate for 35-37 days (dioestrous group; $n=2$; Fig. 1a). These bitches were killed at the end of treatment. Four bitches that were treated with oestradiol benzoate and then megestrol acetate were killed at 3 weeks (mid-anoestrous group; $n=2$; Fig. 1 b) and 9 weeks (late anoestrous group; $n=2$; Fig. 1c) after treatment. Untreated control ovariectomized bitches ( $n=1$ per group) were killed at the same time as treated animals.

\section{Experiment 2}

This experiment investigated whether degeneration of the luminal epithelium of the uterus in the bitch reflects insufficient concentrations of plasma progestagen (Chu et al., 2001b). Twelve ovariectomized bitches were treated with oestradiol benzoate and then megestrol acetate (as the simulated dioestrous group, Expt 1), and were then either treated with $0.5 \mathrm{mg}$ megestrol acetate $\mathrm{kg}^{-1}$ (decreased dose group, $n=3$; Fig. 1d) or with $2 \mathrm{mg}$ megestrol acetate $\mathrm{kg}^{-1}$ (standard dose group, $n=3$ ) each day for a further 3 weeks, or were treated with 3 ( 1 week), 4 ( 1 week) and 5 (1 week) mg megestrol acetate $\mathrm{kg}^{-1}$ (increased dose group, $n=3$; Fig. 2a), or received no treatment (withdrawal dose group $(n=3))$. The withdrawal dose group comprised two bitches in Expt 1 (simulated mid-anoestrous group) plus an additional bitch. All bitches were killed at the end of the treatment period.

\section{Experiment 3}

This experiment investigated whether $\mathrm{CEH}$ can be induced by a suture placed in the uterine lumen of ovariectomized 
Table 1. Relative densitometric values (mean $\pm \mathrm{SE}$, zero values included in the mean) of matrix metalloproteinases (MMP) from the endometrium of ovariectomized bitches treated with oestradiol benzoate and then megestrol acetate to simulate pro-oestrus, oestrus, dioestrus, mid-anoestrus and late anoestrus, and in untreated ovariectomized bitches (controls)

\begin{tabular}{|c|c|c|c|c|c|c|c|c|c|}
\hline \multirow{2}{*}{$\begin{array}{l}\text { Simulated stages/ } \\
\text { groups }\end{array}$} & \multirow{2}{*}{$\mathrm{DCl}$} & \multicolumn{3}{|c|}{ MMP-2 } & \multicolumn{2}{|c|}{ MMP-7 } & \multicolumn{3}{|c|}{ MMP-9 } \\
\hline & & Active form & Latent form & Total & Latent form* & Total & Active form & Latent form & Total \\
\hline $\begin{array}{l}\text { Pro-oestrus } \\
(n=2)\end{array}$ & 0 & $31.5 \pm 1.9$ & $144.4 \pm 1.1$ & $118.4 \pm 1.3$ & - & - & - & 13.9 & 10.6 \\
\hline $\begin{array}{l}\text { Oestrus } \\
(n=2)\end{array}$ & 0 & $50.0 \pm 16.7$ & $81.7 \pm 8.3$ & $74.4 \pm 10.3$ & - & - & - & 11.1 & 8.5 \\
\hline $\begin{array}{l}\text { Dioestrus } \\
(n=2)\end{array}$ & 1 & $44.4 \pm 18.5$ & $64.4 \pm 6.7$ & $59.8 \pm 9.4$ & - & - & - & $9.7 \pm 1.4$ & $7.4 \pm 1.1$ \\
\hline $\begin{array}{l}\text { Late anoestrus } \\
\qquad(n=2)\end{array}$ & 0 & $16.7 \pm 1.9$ & $21.7 \pm 13.9$ & $20.5 \pm 11.1$ & - & - & - & $13.9 \pm 2.8$ & $10.6 \pm 2.1$ \\
\hline $\begin{array}{l}\text { Pooled values }^{\dagger} \\
\quad(n=8)\end{array}$ & 0.25 & $35.7 \pm 7.4^{a}$ & $78.1 \pm 25.5$ & $68.3 \pm 20.2^{\mathrm{ab}}$ & - & - & - & $12.2 \pm 1.1$ & $9.3 \pm 0.8$ \\
\hline $\begin{array}{l}\text { Mid-anoestrus } \\
(n=2)\end{array}$ & 4 & $107.4 \pm 7.4^{b}$ & $124.4 \pm 24.4$ & $120.5 \pm 20.5^{b}$ & $50 \pm 50$ & $50 \pm 50$ & $50 \pm 50$ & $56.9 \pm 43.1$ & $55.3 \pm 44.7$ \\
\hline $\begin{array}{l}\text { Control } \\
(n=5)\end{array}$ & 0 & $21.0 \pm 1.6^{a}$ & $67.6 \pm 7.1$ & $50.3 \pm 4.7^{a}$ & - & - & - & $24 \pm 1.7$ & $9.9 \pm 0.3$ \\
\hline $\begin{array}{l}\text { Withdrawal dose } \\
(n=3)\end{array}$ & 4 & $105.0 \pm 6.3^{b}$ & $106.7 \pm 4.3^{c}$ & $106.2 \pm 4.7^{b}$ & $33.3 \pm 33.3$ & $33.3 \pm 33.3$ & $33.3 \pm 33.3$ & $51.1 \pm 24.4$ & $46.9 \pm 26.6$ \\
\hline $\begin{array}{l}\text { Decreased dose } \\
(n=3)\end{array}$ & 4 & $41.8 \pm 2.3^{a}$ & $70.0 \pm 5.8^{b}$ & $62.4 \pm 4.8^{a}$ & - & - & - & $26 \pm 2.7$ & $19.8 \pm 2.0$ \\
\hline $\begin{array}{l}\text { Standard dose } \\
\quad(n=3)\end{array}$ & 3 & $44.3 \pm 7.0^{\mathrm{a}}$ & $41.9 \pm 4.5^{\mathrm{a}}$ & $42.5 \pm 5.0^{\mathrm{a}}$ & - & - & - & $21.6 \pm 0.7$ & $16.4 \pm 0.5$ \\
\hline $\begin{array}{l}\text { Increased dose } \\
\quad(n=3)\end{array}$ & 1 & $51.8 \pm 9.5^{a}$ & $53.5 \pm 8.1^{a b}$ & $53.0 \pm 4.0^{\mathrm{a}}$ & - & - & - & $17.8 \pm 2.7$ & $13.6 \pm 2.0$ \\
\hline
\end{tabular}

The ovariectomized bitches were treated initially with oestradiol benzoate for 11-12 days and megestrol acetate for $35-37$ days ( 2 mg $\mathrm{kg}^{-1}$ per day). The bitches were killed after a further 3 weeks without treatment (withdrawal dose group, $n=3$ ), after treatment with 0.5 mg megestrol acetate kg ${ }^{-1}$ per day (decreased dose group, $n=3$ ) or with $2 \mathrm{mg}$ megestrol acetate $\mathrm{kg}^{-1}$ per day (standard dose group, $n=3$ ), or after treatment on successive weeks with 3,4 and 5 mg megestrol acetate $\mathrm{kg}^{-1}$ per day (increased dose group, $n=3$ ).

*This band was observed only in extract from one simulated mid-anoestrous bitch; this extract ran in all gels as control.

${ }^{+}$Values for bitches with low degenerative cell index ( $\mathrm{DCl}$; simulated pro-oestrus, oestrus, dioestrus and late anoestrus).

$\mathrm{DCl}$ reflects the number of degenerated luminal epithelial cells in histological sections on a scale of 0 (no cells) to 4 (> $75 \%$ cells).

(-): no band.

${ }^{a b c}$ Values within columns with different superscripts are significantly different $(P<0.05)$.

bitches treated with oestrogen and progestagen (Chu et al., 2001a). In five bitches, a suture (silk or nylon, $0.5 \mathrm{~mm}$ in diameter) was placed in the lumen of one uterine horn at the time of ovariectomy. The surgical silk (Mersilk, Ethicon, Edinburgh, 1G; $n=2$ bitches) or nylon suture (Ethilon, Ethicon, Edinburgh, 1G; $n=3$ bitches) was inserted into the lumen of the right uterine horn and fastened at each end. Three of these bitches were treated with oestradiol benzoate (11 days) and then megestrol acetate (days 36-38), and were killed at the end of treatment. Two bitches received no hormone treatment and served as controls. All bitches were killed at the end of treatments. Samples were taken for uterine histology and uterine microbiology. CEH was induced in one hormone-treated bitch (horn with suture only; Fig. 2b), and CEH plus pyometra (both uterine horns; Fig. 2c) in the remaining two hormone-treated bitches. The control bitches did not develop CEH or pyometra. Bacteria (Streptococcus canis, beta haemolytic Streptococci) were isolated from uteri with $\mathrm{CEH}$ plus pyometra, but not from uteri with $\mathrm{CEH}$ alone.

\section{Experiment 4}

Four intact bitches were killed at $2(n=1), 3(n=2)$ and 11 weeks $(n=1)$ post partum. In addition, uterine tissues were collected during ovariohysterectomy surgery from two dioestrous bitches with naturally occurring $\mathrm{CEH}$ with pyometra associated with infection with Escherichia coli.

Tissues from both uterine horns were fixed in Bouin's solution for conventional histological preparation. The sections were stained with haematoxylin and eosin. The remaining uterine tissues, adjacent to the sites of tissues taken for histology, were stored at $-70^{\circ} \mathrm{C}$.

\section{Quantification of degeneration in the luminal epithelium}

The quantification of the luminal epithelial cells with degeneration in Expts 1, 2 and 3 was performed using the 
Table 2. Relative densitometric values (mean $\pm \mathrm{SE}$, zero values are included in the mean) of matrix metalloproteinases (MMP) from the endometrium of ovariectomized bitches (with suture in the lumen of the uterine horn and treated with oestradiol benzoate for 11-12 days and then megestrol acetate for 35-37 days) with cystic endometrial hyperplasia $(\mathrm{CEH} ; n=1)$ and CEH plus pyometra ( $n=2)$ or in ovariectomized bitches with suture but no hormone treatment (suture control; $n=2)$, and from the endometrium of bitches 2 weeks $(n=1)$,

3 weeks $(n=2)$ and 11 weeks $(n=1)$ after birth and in intact bitches with cystic endometrial hyperplasia plus pyometra $(n=2)$

\begin{tabular}{|c|c|c|c|c|c|c|c|c|c|}
\hline \multirow[b]{2}{*}{ Groups } & \multirow[b]{2}{*}{$\mathrm{DCl} *$} & \multicolumn{3}{|c|}{ MMP-2 } & \multicolumn{2}{|c|}{ MMP-7 } & \multicolumn{3}{|c|}{ MMP-9 } \\
\hline & & Active form & Latent form & Total & Latent form & Total & Active Form & Latent Form & Total \\
\hline \multicolumn{10}{|l|}{$\mathrm{CEH}(n=1)$} \\
\hline $\begin{array}{l}\text { Uterine horn } \\
\text { with suture }\end{array}$ & 0 & 87.9 & 79.9 & 82.3 & - & - & - & 82.8 & 57.6 \\
\hline $\begin{array}{l}\text { Uterine horn } \\
\text { without suture }\end{array}$ & $e^{0}$ & 54.5 & 51.9 & 52.7 & - & - & - & 39.1 & 27.2 \\
\hline $\begin{array}{l}\text { CEH plus } \\
\text { pyometra }(n=2)\end{array}$ & 0 & $168.9 \pm 76.5$ & $83.1 \pm 12.3$ & $108.9 \pm 31.6$ & $233.3 \pm 33.3$ & $233.3 \pm 33.3$ & $458.9 \pm 191.1$ & $275 \pm 7.8$ & $331 \pm 52.7$ \\
\hline $\begin{array}{l}\text { Suture control } \\
\qquad(n=2)\end{array}$ & 0 & $31.8 \pm 3.0$ & $31.5 \pm 13.3$ & $31.6 \pm 10.2$ & - & - & - & $25.0 \pm 9.4$ & $17.4 \pm 6.5$ \\
\hline $\begin{array}{l}2 \text { weeks after } \\
\text { birth }(n=1)\end{array}$ & 4 & 231.6 & 250.8 & 241.6 & 156.3 & 156.3 & 191.7 & 254.5 & 227.6 \\
\hline $\begin{array}{l}3 \text { weeks after } \\
\text { birth }(n=2)\end{array}$ & 4 & $232.2 \pm 34.5$ & $201.6 \pm 31.7$ & $216.3 \pm 33.1$ & $114.1 \pm 4.4$ & $114.1 \pm 4.4$ & $170.2 \pm 60.1$ & $214.8 \pm 85.9$ & $195.7 \pm 74.8$ \\
\hline $\begin{array}{l}11 \text { weeks after } \\
\text { birth }(n=1)\end{array}$ & 2 & 54 & 107.4 & 81.8 & - & - & 63.3 & 49.7 & 55.5 \\
\hline $\begin{array}{l}\text { Naturally } \\
\text { occurring CEH } \\
\text { plus pyometra } \\
(n=2)\end{array}$ & 3 & $157.5 \pm 41.4$ & $252.6 \pm 45.8$ & $207 \pm 43.7$ & $148.1 \pm 40.3$ & $148.1 \pm 40.3$ & $593.6 \pm 21.1$ & $411.4 \pm 14.8$ & $489.6 \pm 17.5$ \\
\hline
\end{tabular}

*DCl: degenerative cell index reflects the number of degenerated luminal epithelial cells in histological sections on a scale of 0 (no cells) to 4 (> 75\% cells). $(-)$ : no band.

method of Watts (1998). The luminal epithelium was examined for signs of degeneration (pyknotic, shrunken nuclei and highly vacuolated cytoplasm) under a microscope at a magnification of $\times 1000$. Twenty adjacent fields of the luminal epithelium were examined. The percentage of degenerated luminal epithelial cells was calculated by dividing the number of luminal epithelial cells with signs of degeneration by the total number of luminal epithelial cells counted $\times 100$. The degenerative cell index $(\mathrm{DCl})$ was defined as the percentage of the luminal epithelial cells that showed signs of degeneration $(0=$ no degenerated cells, $1=<25 \%$ cells with degeneration, $2=25-50 \%$ cells with degeneration, $3=51-75 \%$ cells with degeneration and $4=>75 \%$ cells with degeneration).

\section{Extraction of tissues for MMP}

Uterine tissues were thawed, and perimetrium and myometrium were removed. The endometrial tissue was then weighed and homogenized using a mechanical homogenizer for 15 min using Triton buffer containing $10 \mathrm{mmol}$ $\mathrm{CaCl}_{2} \mathrm{I}^{-1}$ and $0.25 \%(\mathrm{v} / \mathrm{v})$ Triton-X100 (1 ml buffer per $100 \mathrm{mg}$ endometrium). No proteinase inhibitors were added. Throughout the entire procedure, all samples, solutions and equipment were kept on ice at $4^{\circ} \mathrm{C}$. Each homogenate was transferred to a $1.5 \mathrm{ml}$ Eppendorf tube and centrifuged in a microcentrifuge at $13000 \mathrm{~g}$ for $30 \mathrm{~min}$ at $4^{\circ} \mathrm{C}$. The supernatant was stored at $-20^{\circ} \mathrm{C}$.

\section{Gelatin and casein zymography}

Proteinase content of extracted samples was analysed by zymography on $10 \%$ SDS-polyacrylamide gels containing $10 \mathrm{mg}$ gelatin ml-1 or $10 \mathrm{mg} \beta$-casein $\mathrm{ml}^{-1}$ (all reagents from Bio-Rad Laboratories, North Ryde) under non-reducing conditions, using the Bio-Rad miniprotean II equipment (Bio-Rad Laboratories). After washing the gels in a buffer containing $50 \mathrm{mmol}$ Tris- $\mathrm{HCl} \mathrm{I}^{-1}, 5 \mathrm{mmol} \mathrm{CaCl} \mathrm{I}^{-1}, 1 \mu \mathrm{mol}$ $\mathrm{ZnCl}_{2} \mathrm{I}^{-1}, 0.01 \%(\mathrm{w} / \mathrm{v}) \mathrm{NaN}_{3}(\mathrm{pH} 7.5)$ and $2.5 \%(\mathrm{v} / \mathrm{v})$ Triton$\mathrm{X} 100$, the gels were incubated in the same buffer without Triton-X100 at $37^{\circ} \mathrm{C}$ for $43 \mathrm{~h}$ and stained with Coomassie brilliant blue G250. Gelatinase or caseinase activities were visualized by negative staining, and bands were identified by comparison with standard preparations of pure human MMPs and with molecular mass markers (Bio-Rad Laboratories). The identification of all bands of MMPs was confirmed by incubation of parallel gels in the presence of EDTA ( $5 \mathrm{mmol} \mathrm{I}^{-1}$ ), which specifically inhibits MMP but not other classes of protease. The activity of MMP-7 was detected using molecular mass markers only, because of the 

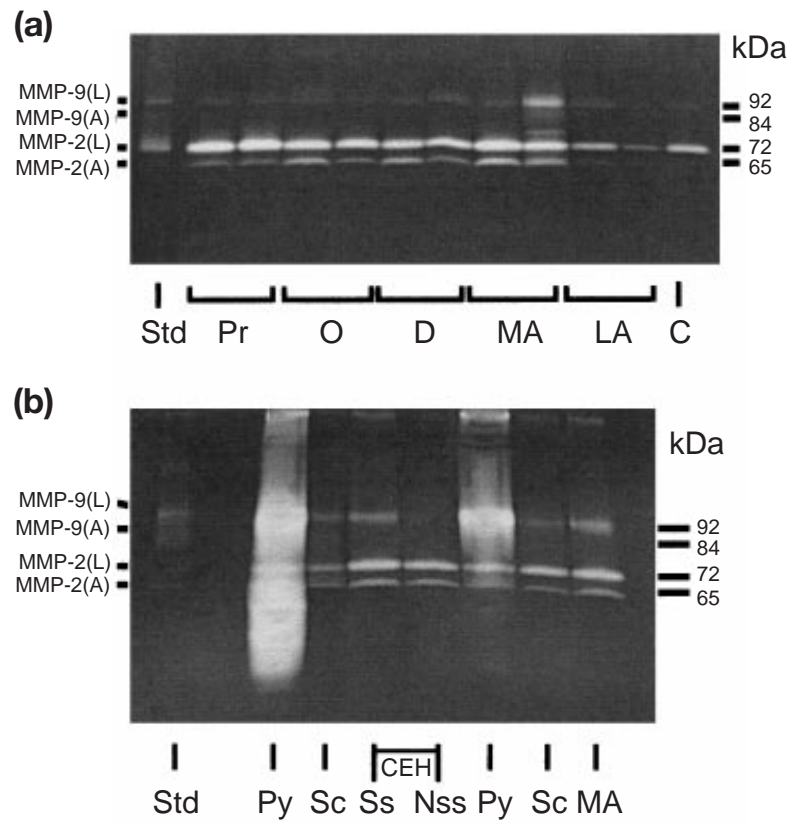

(c)

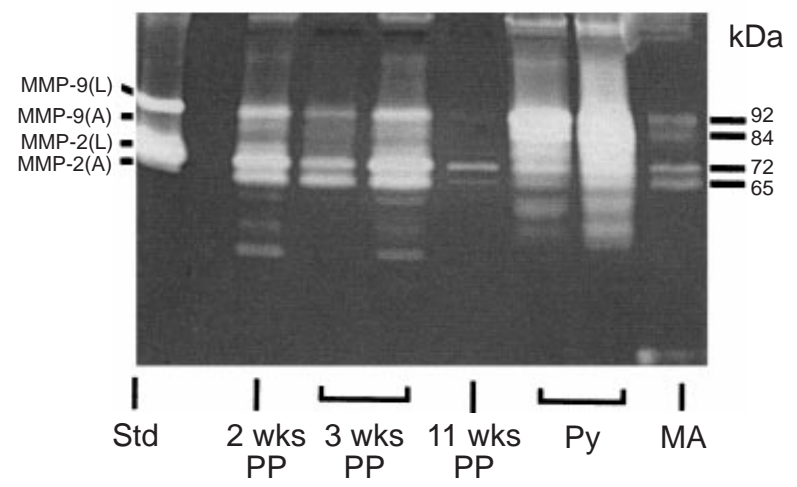

Fig. 3. (a) Gelatin zymogram of matrix metalloproteinase (MMP)-2 and -9 of tissue homogenates of endometrium collected from treated bitches in simulated pro-oestrus $(\mathrm{Pr})$, oestrus $(\mathrm{O})$, dioestrus (D), mid-anoestrus (MA) and late anoestrus (LA), and one control (C) bitch. (b) Gelatin zymogram of MMP-2 and -9 in tissue homogenates of endometrium collected from suture control bitches (Sc; suture alone but no hormone treatment), suture treated bitch with cystic endometrial hyperplasia (CEH) (Ss: uterine horn with suture; Nss: uterine horn without suture), suture treated bitches with pyometra (Py) and from one bitch during simulated midanoestrus (MA). (c) Gelatin zymogram of MMP-2 and -9 of tissue homogenates of endometrium collected from bitches at 2, 3 and 11 weeks post partum (PP), bitches with naturally occurring cystic endometrial hyperplasia plus pyometra (Py) and from one bitch during simulated mid-anoestrus (MA). Latent and active MMP-2 and -9 were identified by comparison with purified human standards (Std; lane 1). The band at $92 \mathrm{kDa}$ represents the latent form of MMP-9 and the band at $84 \mathrm{kDa}$, the active form. The band at $72 \mathrm{kDa}$ represents the latent form of MMP-2 and the band at $65 \mathrm{kDa}$, the active form.

lack of a standard preparation of human MMP-7. Activity of similar molecular mass to human MMP-7 was assumed to be canine MMP-7.

\section{Quantification of MMP}

The amount of each MMP band (mean absorbance) was quantified by densitometric analysis of zymograms using the GS-710 Calibrated Imaging Densitometer (scanner) with Quantity One software (version 4.1; Bio-Rad Laboratories) set on a black and white photograph with 256 grey shades. The intensity of each band (densitometric reading) was computed as the volume of the band $\times$ mean absorbance. The densitometric reading for MMP-2, -7 and -9 (latent or active form) and the total MMP-2, -7 and -9 (latent plus active forms) were determined for each sample. The relative densitometric units were calculated as densitometric values $(\times 100)$ relative to a control extract (from a bitch in simulated mid-anoestrus) that was run in each gel. Thus, the relative densitometric units for each bitch for each MMP of the latent, active and total forms were the densitometric readings for each bitch relative to the densitometric reading for the latent, active and total MMP of the control bitch. Areas with no band visible were ascribed a value of 0 . Comparisons were made only between samples run on a single gel.

\section{Statistical analysis}

Means ( \pm SEM) were calculated for each band, representing MMP-2, -7 and -9 (latent, active and total forms). Means of variables were compared using a one-way ANOVA and Tukey's test with the computer program SPSS (SPSS Inc., Chicago, IL). The level of significance was set at $P<0.05$.

\section{Results}

The degenerative cell index (DCl) of the luminal epithelial cells was high $(\geqslant 3)$ in the simulated mid-anoestrous, withdrawal dose, decreased dose and standard dose groups, and in bitches at 2 and 3 weeks post partum, but was low $(\leqslant 2)$ in the simulated dioestrus, increased dose and naturally occurring $\mathrm{CEH}$ with pyometra groups, and in the bitch at 11 weeks post partum. In bitches with $\mathrm{CEH}$ plus pyometra, most of the luminal epithelium had sloughed off, and of the luminal epithelial cells remaining, only a few showed signs of degeneration. No degeneration of the luminal epithelial cells was observed in all the other groups (Tables 1 and 2). The MMPs detected were MMP-2 (latent and active forms), MMP-7 (latent form) and MMP-9 (latent and active forms). The active form of MMP-7 was not detected (Figs 3-6; Tables 1 and 2). Confirmation that bands contained MMPs was obtained by their inhibition in gels incubated in the presence of EDTA. Of the bitches in Expts 1 and $2(n=25)$, marked degeneration $(\mathrm{DCl}=4)$ was observed in six bitches and less severe degeneration $(\mathrm{DCl}=1-3)$ in eight bitches and no degeneration $(\mathrm{DCl}=0)$ in 11 bitches (Table 1 ).

\section{Experiment 1}

As no differences in MMP activities were observed in the simulated pro-oestrous, oestrous, dioestrous and late 

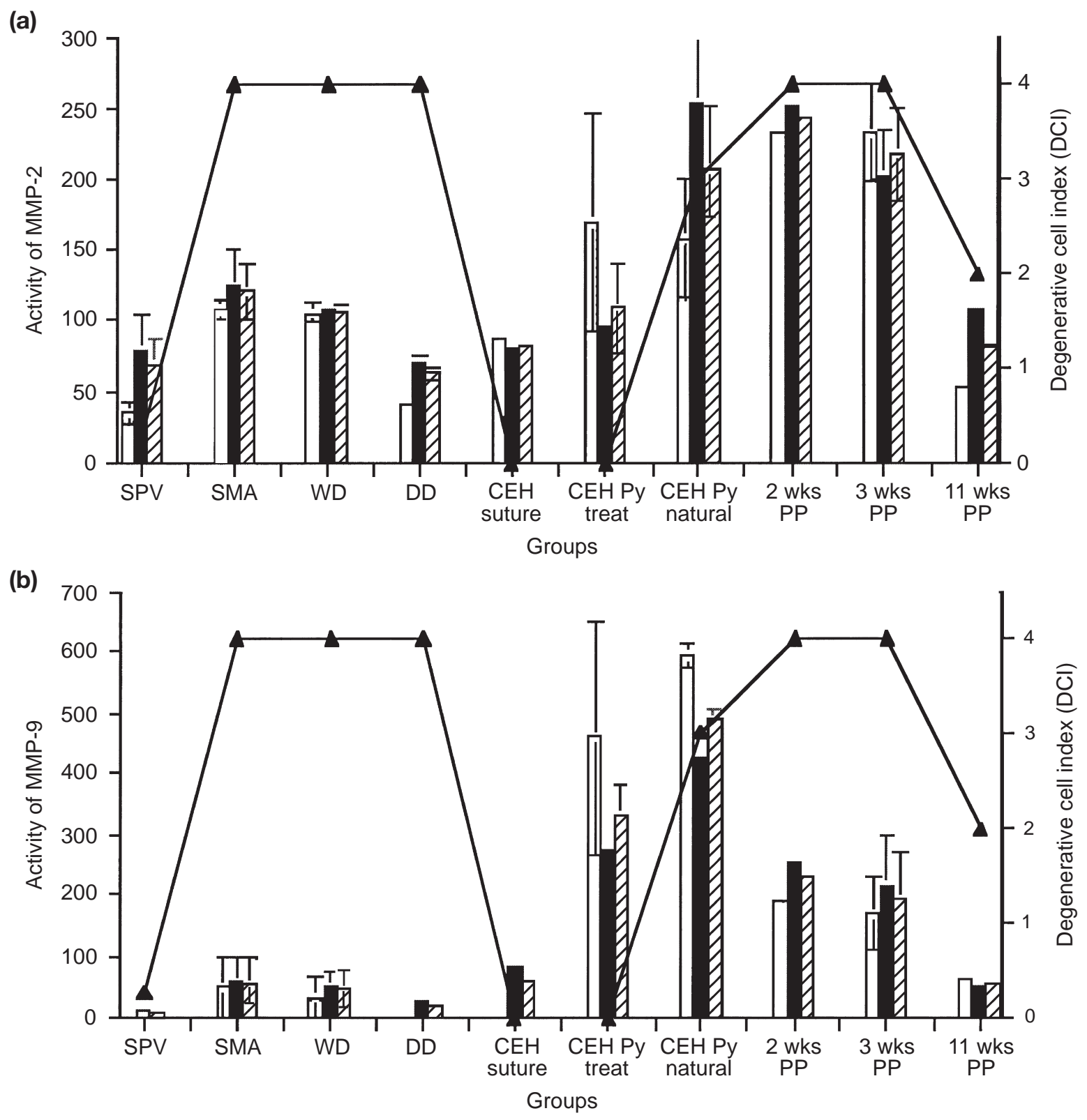

Fig. 4. The degenerative cell index (DCl) of uterine luminal epithelium and the activity of (a) matrix metalloproteinase (MMP)-2 and (b) MMP-9 in the canine endometrium. $\mathbf{\Delta}$ : DCl; $\mathbf{\square}$ : latent MMP; : $\square$ total MMP; $\square$ : active MMP. SPV: simulated pooled values for pro-oestrus, oestrus, dioestrus and late anoestrus; SMA: simulated mid-anoestrus; WD: withdrawal dose; DD: decreased dose; $\mathrm{CEH}$ suture: cystic endometrial hyperplasia (uterine horn with suture); $\mathrm{CEH} P \mathrm{Py}$ treat: $\mathrm{CEH}$ with pyometra (treatment-induced); $\mathrm{CEH}$ Py natural: $\mathrm{CEH}$ with pyometra (naturally occurring); PP: post partum.

anoestrous groups and these bitches all had low DCl, these data were pooled for subsequent analyses. The active form of MMP-2 was greater $(P<0.05)$ in the simulated midanoestrous group $(n=2$; with a high degenerative cell index) than in the control $(n=5)$ and pooled $(n=8)$ groups (with low DCl; Fig. 4a; Table 1). Total MMP-2 was also greater $(P<0.05)$ in the simulated mid-anoestrous group than in control bitches (Table 1). One bitch at simulated mid-anoestrus displayed stronger bands of MMP-7 (latent form) and MMP-9 (active form) than did bitches at the other simulated stages (Figs 3 and 5; Table 1). MMP-9 (latent and total forms) activities were similar $(P \geqslant 0.05)$ for control animals $(n=5)$, and bitches with high $(n=2)$ and low $(n=8)$ degenerative cell indices (Table 1$)$.

\section{Experiment 2}

The activities of MMP-2 (latent, active and total forms) in the withdrawal dose group were higher $(P<0.05)$ than those in all the other groups (Fig. 4a; Table 1). Moreover, the 

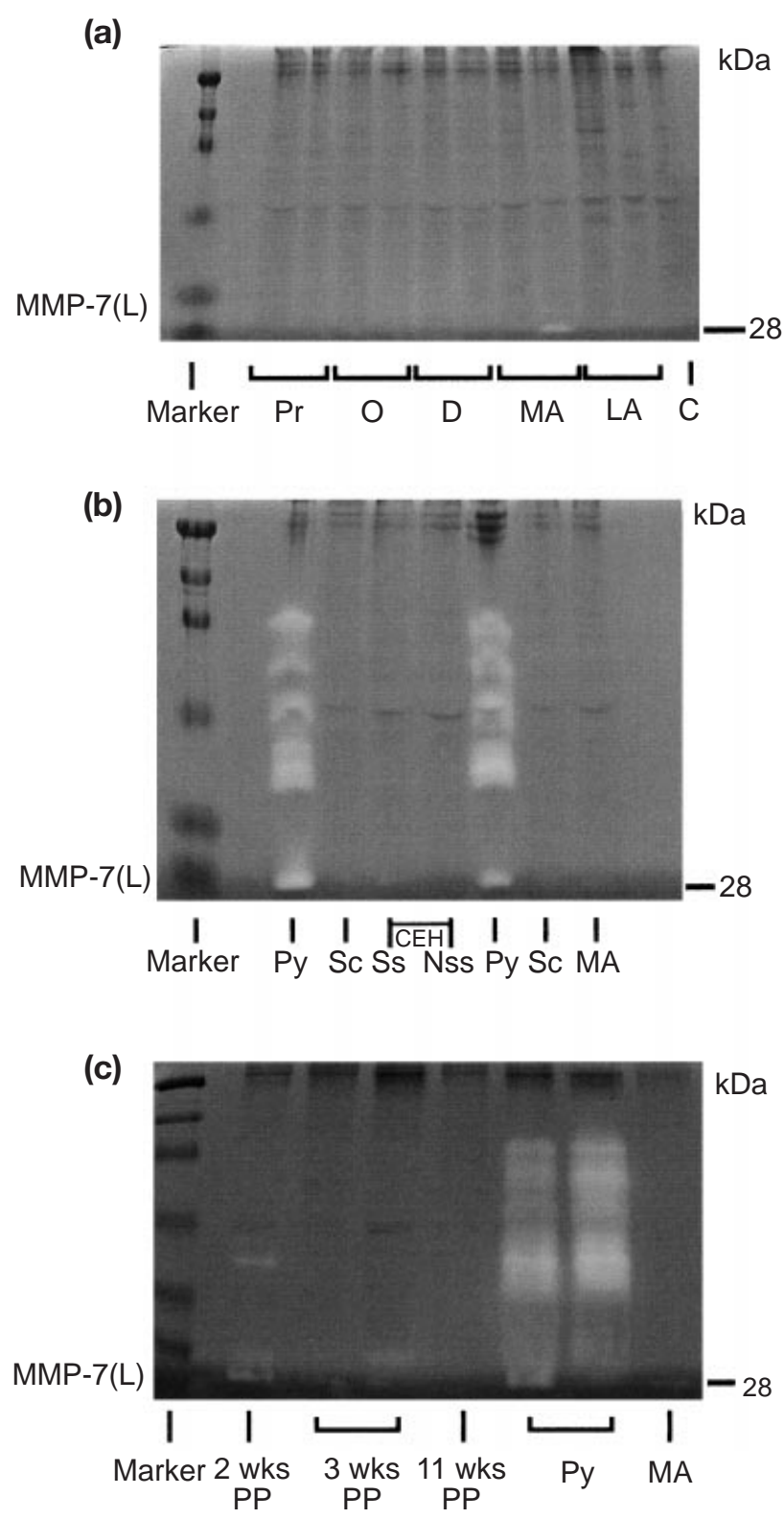

Fig. 5. (a) Casein zymogram showing matrix metalloproteinase (MMP)-7 in tissue homogenates of endometrium collected from treated bitches in simulated pro-oestrus $(\mathrm{Pr})$, oestrus $(\mathrm{O})$, dioestrus (D), mid-anoestrus (MA) and late anoestrus (LA), and one control (C) bitch. (b) Casein zymogram showing MMP-7 in tissue homogenates of endometrium taken from suture control bitches (Sc; suture alone but no hormone treatment), suture treated bitch with cystic endometrial hyperplasia (CEH) (Ss: uterine horn with suture; Nss: uterine horn without suture), suture treated bitches with pyometra (Py) and one bitch during simulated mid-anoestrus (MA). (c) Casein zymogram of MMP-7 of tissue homogenates of endometrium taken from bitches at 2, 3 and 11 weeks post partum (PP), bitches with naturally occurring cystic endometrial hyperplasia plus pyometra (Py) and from one bitch during simulated midanoestrus (MA). Latent MMP-7 was identified by comparison with a molecular mass marker (Bio-Rad; lane 1) and by its disappearance in gels incubated with EDTA. The band at $28 \mathrm{kDa}$ probably represents the latent form of MMP-7 because it is of similar molecular mass to human MMP-7. activity of MMP-2 (latent form) in the decreased dose group was higher $(P<0.05)$ than that in the standard dose group (Table 1). In one bitch in the withdrawal dose group, the MMP indices of MMP-7 (latent form) and MMP-9 (active form) were stronger than those in the decreased dose, standard dose and increased dose groups (Figs 4b and 6; Table 1).

\section{Experiment 3}

In the bitches with $\mathrm{CEH}$ plus pyometra, the activities of MMP-2 (latent, active and total forms), MMP-7 (latent and total forms) and MMP-9 (latent, active and total forms) overall were higher than those in suture control and bitches with $\mathrm{CEH}$ alone (Figs 3-6; Table 2), although it was not possible to analyse the data statistically due to small numbers. There is a strong indication from analysis by casein zymography that various forms of other MMPs with caseinase activity (for example, MMP-1 and MMP-3) may have been present in bitches with $\mathrm{CEH}$ plus pyometra, but the bands (Fig. 5) have not been fully identified due to lack of information regarding canine MMP or specific antisera. However, there were no MMPs with activity against casein in other groups. Histological observation showed that the superficial glands of the uterine horns with suture were hyperplastic and markedly dilated (Fig. 2b), and very few leucocytes were detected in the stroma or in the luminal and glandular epithelia in the bitch with $\mathrm{CEH}$. However, in bitches with $\mathrm{CEH}$ plus pyometra, most of the epithelial cells lining lumen and the superficial glands had desquamated, and only occasional sites were seen with intact cells (Fig. 2c). Most of the glands were markedly cystic and dilated. Many plasma cells and neutrophils were found in the stroma (Chu, 2000; Fig. 7).

\section{Experiment 4}

MMP-2 (latent, active and total forms) was higher in bitches at 2 and 3 weeks post partum than in all the simulated and control bitches, bitches treated with suture and bitches at 11 weeks post partum (Figs 3 and 4a; Tables 1 and 2). MMP-9 (latent, active and total forms) was higher in the bitches at 2 and 3 weeks post partum than in all the simulated, control and the bitch at 11 weeks post partum (Figs 3 and 4b; Tables 1 and 2). MMP-7 (latent and total forms) was higher in the bitches at 2 and 3 weeks post partum than in all other bitches except the treated and intact bitches with $\mathrm{CEH}$ plus pyometra (Figs 5 and 6; Tables 1 and 2). The histological examination of the uterus from naturally occurring $\mathrm{CEH}$ with pyometra showed that most of the findings were similar to those of experimentally induced $\mathrm{CEH}$ plus pyometra. In the bitches with naturally occurring $\mathrm{CEH}$ plus pyometra, the luminal epithelial cells were markedly degenerated (Table 2) but had not desquamated. Other histological features were similar to those of sutureinduced bitches (Expt 3). Histological examination of the uterus from bitches at 2 and 3 weeks post partum revealed marked degeneration $(\mathrm{DCl}=4)$ of the luminal epithelial 


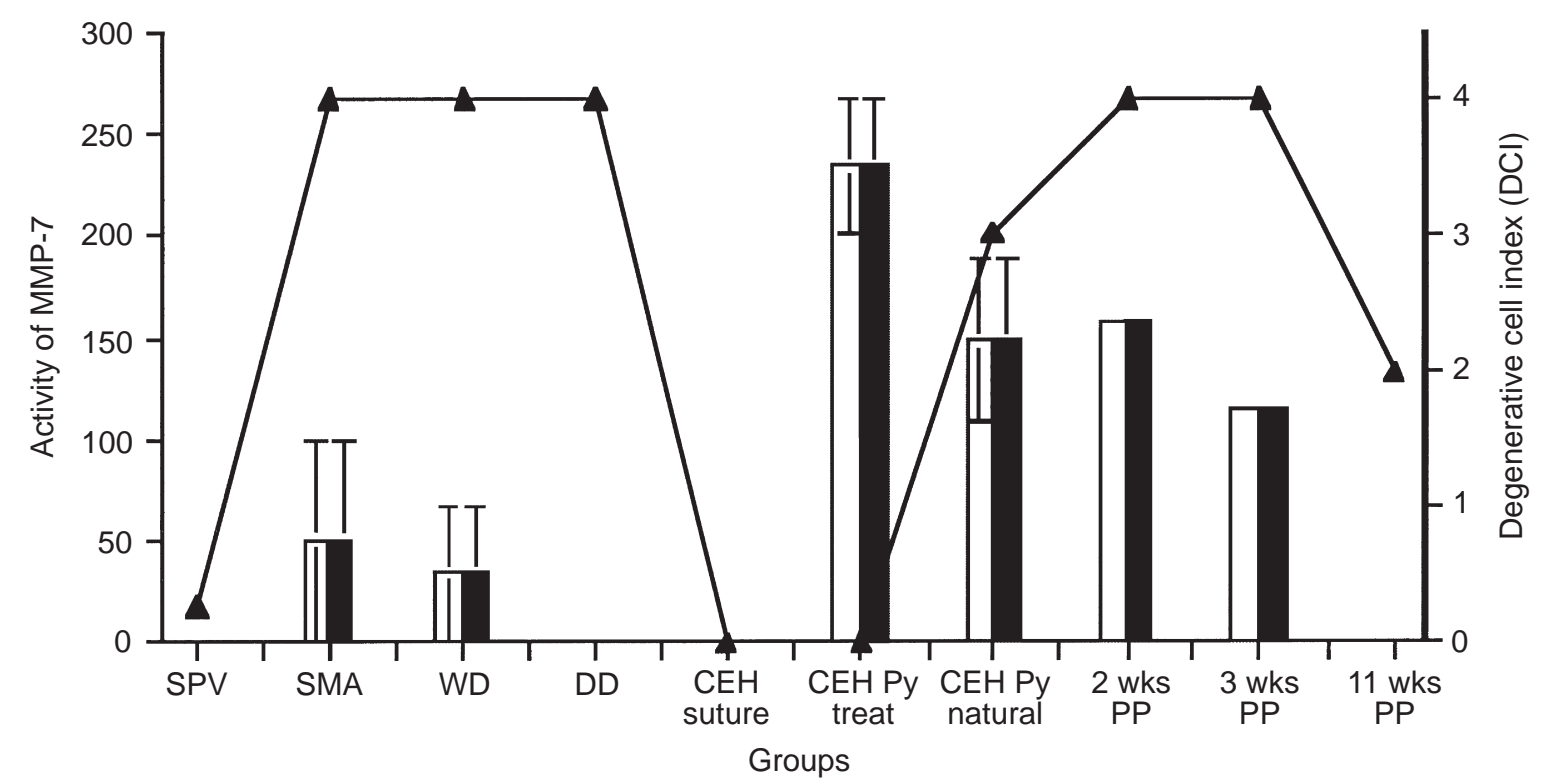

Fig. 6. The degenerative cell index (DCl) of uterine luminal epithelium and the activity of matrix metalloproteinase (MMP)-7 in the canine endometrium. $\mathbf{\Delta}$ : DCl; $\square$ : latent MMP-7; $\mathbf{\square}$ : total MMP-7. SPV: simulated pooled values for prooestrus, oestrus, dioestrus and late anoestrus; SMA: simulated mid-anoestrus; WD: withdrawal dose; DD: decreased dose; CEH suture: cystic endometrial hyperplasia (uterine horn with suture); $\mathrm{CEH}$ Py treat: CEH with pyometra (treatment-induced); CEH Py natural: CEH with pyometra (naturally occurring); PP: post partum.

cells, and many neutrophils, lymphocytes and plasma cells were present in the stroma that was oedematous. However, less severe degeneration $(\mathrm{DCl}=2)$ of the luminal epithelial cells and some lymphocytes and macrophages in the stroma were observed in the bitch at 11 weeks post partum.

\section{Discussion}

The results of the present study demonstrate that MMPs play a role in endometrial breakdown in bitches under certain conditions as they do in other species. However, MMPs do not appear to be involved with degeneration of the luminal epithelium, as no clear differences were observed overall in the activity of MMPs in the endometrium of bitches with (14 of 25 bitches; Expts 1 and 2) or without (11 of 25 bitches) luminal epithelial degeneration.

The reason for the higher MMP-2 (active form) activities in bitches in simulated mid-anoestrus is unclear. In humans, MMP-2 is often an epithelial cell product (Zhang et al., 2000) and its mRNA is expressed throughout the entire menstrual cycle (Rodgers et al., 1993; Irwin et al., 1996). However, MMP-2 is widely expressed and secreted in many cells and tissues, and is not regulated predominantly at the level of transcription, but rather at the level of activation. This is brought about largely by the action of the membrane-type (MT)-MMP, which is regulated at transcription. The reason for the higher concentrations of MMP-7 (latent form) in one simulated mid-anoestrous bitch in the present study is unknown. In human and rhesus monkey endometrium, MMP-7 is an epithelial-specific MMP and has been localized to the luminal and glandular epithelium

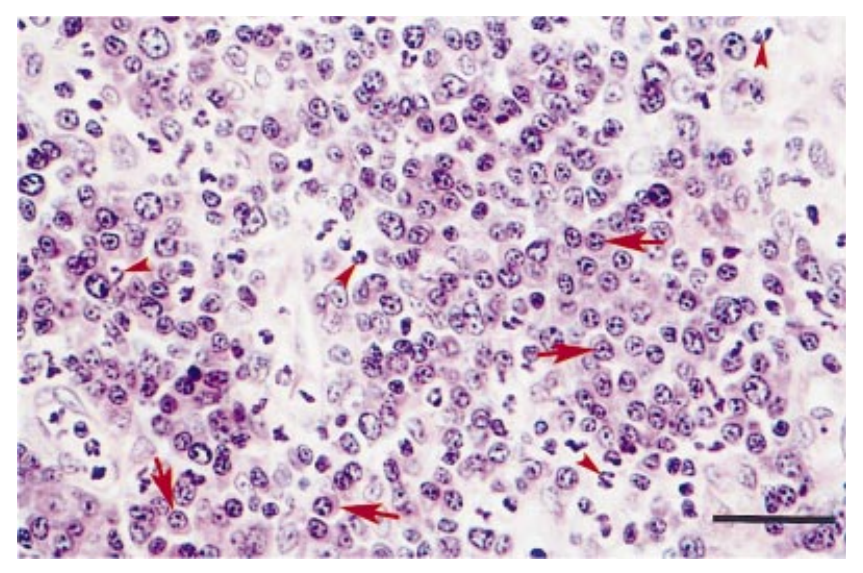

Fig. 7. Light micrograph of a uterine section taken from an ovariectomized bitch (with a nylon suture inserted in the lumen of the uterine horn and treated with oestradiol benzoate for 11 days and then with megestrol acetate for 36 days) with cystic endometrial hyperplasia and pyometra. Note that many plasma cells (arrows) and neutrophils (arrowheads) are present in the stroma. Haematoxylin and eosin stain; scale bar represents $30 \mu \mathrm{m}$.

in the superficial layer but not in the basal layer after menstruation begins (Rodgers et al., 1993; Brenner et al., 1996). MMP-7 is considered to have a role in degrading luminal debris and subsequently facilitating tissue remodelling during the early and mid-proliferative phases but is probably not involved in initiation of menstruation (Hulboy et al., 1997). The reason for the higher concentrations of MMP-9 (active form) in one simulated mid-anoestrous 
bitch could reflect the larger number of neutrophils in the stroma of this bitch than in the other bitch (Chu et al., 2001b). A similar association has been shown in human endometrium in menstrual tissues (Salamonsen and Lathbury, 2000), and neutrophil MMP-9 is considered to have an important role in degrading tissue in menstrual endometrium.

The results for bitches treated with various doses of progestagen (Expt 2) indicate that the withdrawal of progestagen can lead to an increase of MMP-2 activity. Such an effect of progesterone withdrawal was also seen at menstruation in humans (Salamonsen et al., 1997), and probably results from upregulation of MT-MMP expression and consequent pro-MMP-2 activation when progesterone concentrations decrease before menstruation in humans (Zhang et al., 2000). The role of progesterone may be similar in bitches.

The higher activities of MMP-2, -7 and -9 in treated and intact bitches with $\mathrm{CEH}$ plus pyometra than in all other bitches except in the bitches at 2 and 3 weeks post partum indicates that the increased MMPs are probably associated with the inflammatory response of the endometrium in these bitches, characterized by many neutrophils and plasma cells in the stroma (Chu et al., 2001a). Similar high concentrations of MMP-9 in menstrual tissues in humans are also due to MMP-9 positive neutrophils, monocytemacrophages and eosinophils (Salamonsen and Lathbury, 2000). Such high amounts of MMP, associated with the marked desquamation of the luminal epithelium and superficial glands (Chu et al., 2001a), can be considered as part of the defence mechanisms of the uterus, resulting in the shedding of infected tissue.

The increased concentrations of MMPs observed in the bitches at 2 and 3 weeks post partum were associated with remodelling of the uterus. The histological findings were consistent with those described by Al-Bassam et al. (1981) and were characterized by degeneration of the luminal epithelial cells and marked infiltration of leucocytes in the stroma. A similar increase of MMP-7 post partum has been described in rats (Woessner, 1996; Wolf et al., 1996). The decreased concentrations of MMP observed in a bitch at 11 weeks post partum occurred when the remodelling process was almost complete (Al-Bassam et al., 1981).

In summary, MMP-2 (latent and active forms) and MMP9 (latent form) were detected in the endometrium of all bitches. The latent form of MMP-7 and the active form of MMP-9 were observed only in one bitch of each of the withdrawal dose and simulated mid-anoestrous groups, and in the bitches with $\mathrm{CEH}$ plus pyometra and in those at 2 and 3 weeks post partum. This finding probably reflects the presence of large numbers of leucocytes in the endometrial stroma in these bitches. Increased activity of MMP-2 was associated with plasma progestagen withdrawal. The present study shows that endometrial MMPs may play an important role in $\mathrm{CEH}$ plus pyometra and post partum but they are not likely to be involved with degeneration of the luminal epithelium.
The authors thank A. Misajon and J. Zhang for laboratory advice and assistance, Y. M. M. Chen for the uterine tissues of bitches with naturally occurring $\mathrm{CEH}$ plus pyometra, and M. Williams and D. Kavanagh for care of the dogs. The funding support of the Victorian Canine Association-Canine Research Foundation is gratefully acknowledged.

\section{References}

Al-Bassam MA, Thomson RG and O'Donnell L (1981) Normal postpartum involution of the uterus in the dog Canadian Journal of Comparative Medicine 45 217-232

Brenner RM, Rudolph LA, Matrisian LM and Slayden OD (1996) Nonhuman primate models: artificial menstrual cycles, endometrial matrix metalloproteinases and subcutaneous endometrial grafts Human Reproduction Supplement 11 150-164

Chu Po-yin (2000) The Control of Endometrial Function in the Bitch PhD Thesis, The University of Melbourne

Chu Po-yin, Lee CS, Moore PF and Wright PJ (2001a) Oestrogen and progestagen treated ovariectomised bitch: a model for the study of uterine function Journal of Reproduction and Fertility Supplement $\mathbf{5 7}$ $45-54$

Chu Po-yin, Wright PJ and Lee CS (2001b) Association of endometrial degeneration in bitches with insufficient plasma progestagen concentrations Journal of Reproduction and Fertility Supplement $\mathbf{5 7}$ $35-43$

Hulboy DL, Rudolph LA and Matrisian LM (1997) Matrix metalloproteinases as mediators of reproductive function Molecular Human Reproduction 3 27-45

Irwin JC, Kirk D, Gwatkin RBL, Navre M, Cannon P and Guidice LC (1996) Human endometrial matrix metalloproteinase-2, a putative menstrual proteinase: hormonal regulation in cultured stromal cells and messenger RNA expression during the menstrual cycle Journal of Clinical Investigation 97 438-447

Marbaix E, Kokorine I, Henriet P, Donnez J, Courtoy PJ and Eeckhout Y (1995) The expression of interstitial collagenase in human endometrium is controlled by progesterone and by oestradiol and is related to menstruation Biochemical Journal 305 1027-1030

Rodgers WH, Osteen KG, Matrisian LM, Navre M, Guidice LC and Gorstein F (1993) Expression and localisation of matrilysin, a matrix metalloproteinase, in human endometrium during the reproductive cycle American Journal Obstetrics and Gynecology 168 253-260

Rodgers WH, Matrisian LM, Giudice LC, Dsupin B, Cannon P, Svitek C, Gorstein F and Osteen KG (1994) Patterns of matrix metalloproteinase expression in cycling endometrium imply differential functions and regulation by steroid hormone Journal of Clinical Investigation 94 946-953

Salamonsen LA and Lathbury LJ (2000) Endometrial leukocytes and menstruation Human Reproduction 6 16-27

Salamonsen LA and Woolley DE (1999) Review - menstruation: induction by matrix metalloproteinases and inflammatory cells Journal of Reproductive Immunology $4 \mathbf{4}$ 1-27

Salamonsen LA, Nagase H and Woolley DE (1995) Matrix metalloproteinases and their tissue inhibitors at the ovine trophoblastuterine interface Journal of Reproduction and Fertility Supplement $\mathbf{4 9}$ $29-37$

Salamonsen LA, Butt AR, Hammond FR, Garcia S and Zhang J (1997) Production of endometrial matrix metalloproteinases, but not their tissue inhibitors, is modulated by progesterone withdrawal in an in vitro model for menstruation Journal of Clinical Endocrinology and Metabolism $\mathbf{8 2}$ 1409-1415

Watts JR (1998) Uterine Function and Dysfunction in Bitches PhD Thesis, The University of Melbourne

Wilson CL, Heppner KJ, Rudolph LA and Matrisian LM (1995) The metalloproteinase matrilysin is preferentially expressed in epithelial cells in a tissue-restricted pattern in the mouse Molecular Biology of the Cell 6 851-869 
Woessner JF (1996) Regulation of matrilysin in the rat uterus Biochemistry and Cell Biology 74 777-784

Wolf K, Sandner P, Kurtz A and Moll W (1996) Messenger ribonucleic acid levels of collagenase (MMP-13) and matrilysin (MMP-7) in virgin, pregnant, and postpartum uterus and cervix of rat Endocrinology 137 5429-5434

Zhang J, Hampton AL, Nie G and Salamonsen LA (2000) Progesterone inhibits activation of latent matrix metalloproteinases (MMP)-2 by membrane-type 1 MMP: enzymes coordinately expressed in human endometrium Biology of Reproduction 62 85-94

Received 16 July 2001.

First decision 30 August 2001.

Revised manuscript received 23 November 2001.

Accepted 29 November 2001. 